九州大学学術情報リポジトリ

Kyushu University Institutional Repository

\title{
Rhythmic Response of Rhizome Growth to Light- break in Lotus (Nelumbo nucifera)
}

Masuda, Junichiro

Graduate School of Bioresource and Bioenvironmental Sciences, Kyushu University

Yoshimizu, Shohei

School of Agriculture, Kyushu University

Ozaki, Yukio

Faculty of Agriculture, Kyushu University

Okubo, Hiroshi

Faculty of Agriculture, Kyushu University

https://doi.org/10.5109/9277

出版情報：九州大学大学院農学研究院紀要. 52 (1)，pp.35-38，2007-02-28. Faculty of Agriculture， Kyushu University

バージョン :

権利関係 : 


\title{
Rhythmic Response of Rhizome Growth to Light-break in Lotus (Nelumbo nucifera)
}

\author{
Jun-ichiro MASUDA ${ }^{1 *}$, Shohei YOSHIMIZU ${ }^{2}$, Yukio OZAKI ${ }^{3}$ \\ and Hiroshi OKUBO
}

\author{
Laboratory of Horticultural Science, Division of Agricultural Botany, Department of Plant Resources, \\ Faculty of Agriculture, Kyushu University, Fukuoka 812-8581, Japan \\ (Received November 10, 2006 and accepted December 1, 2006)
}

\begin{abstract}
We examined the response of rhizome growth to red light-break under different short daylengths in lotus (Nelumbo nucifera) seedlings. Maximum inhibitory response of rhizome enlargement to light-break under 10, 8 and $4 \mathrm{hr}$ daylengths occurred 10, 8-10 and 12-14hrs after the beginning of the dark period, respectively. It was found that rhythmic response to light-break is involved in rhizome growth of lotus.
\end{abstract}

\section{INTRODUCTION}

It is commonly recognized that modified parts of stem as tuber, corm and rhizome in geophytes, being used for asexual propagation, are the dormant organs for survival strategy of the plants during unfavorable period for their growth. The mechanisms of the formation of the dormant organs in these geophytes have been poorly understood. It has been known that tuber formation in Solanum tuberosum (Ewing and Struik, 1992; Snyder and Ewing, 1989), Begonia evansiana (Esashi and Nagao, 1958) and Helianthus tuberosus (Hamner and Long, 1939) is dependent on photoperiod. There are, however, no such reports in cormous and rhizomous plants in which the formation of dormant organs depend on environmental factors.

Lotus (Nelumbo nucifera) is an aquatic rhizomous plant. As temperature rises in the early spring, a new rhizome begins to elongate in a single direction with a few floating leaves from the enlarged rhizomes of the previous year. The rhizomes elongate and branch with many upright leaves, and rhizome girth and length become large and short in late summer, respectively. Finally, the rhizomes elongate up to about $11 \mathrm{~m}$ in main stem length and enlarge in three to four distal internodes to survive from incoming winter. Large field (more than $2 \mathrm{~m}^{2} /$ plant) is resultantly required per plant for cultivation. Detailed investigation of the rhizome growth in underground consumes time and labor. Because of the reasons as mentioned above, the dynamics of rhizome transition to storage organ (physiological research) have been poorly understood in this species.

\footnotetext{
1 Laboratory of Horticultural Science, Division of Agricultural Botany, Department of Plant Resources, Graduate School of Bioresource and Bioenvironmental Sciences, Kyushu University, Fukuoka 812-8581, Japan

2 Program of Horticultural Science, Course of Agronomy, Department of Bioresource and Bioenvironment, School of Agriculture, Kyushu University, Fukuoka 812-8581, Japan

${ }^{3}$ Laboratory of Agricultural Ecology, Division of Agricultural Ecology, Department of Plant Resources, Faculty of Agriculture, Kyushu University, Fukuoka 811-2307, Japan

* Corresponding author (E-mail: j-masuda@agr.kyushu-u.ac.jp)
}

We previously demonstrated that in lotus short daylength is a definite requirement for rhizome transition to storage organ (Masuda et al., 2006) by using seedlings. Giving light break in the middle of dark period under short daylength prevented from rhizome increase in girth, and yellow and red lights are the most effective than other light sources (Masuda et al., submitted). These are the similar responses of flowering in an SDP (short day plant) Xanthium strumarium, SDP Glycine max (Parker et al., 1946), LDP (long day plant) Hordeum vulgare (Borthwick et al., 1948) and LDP Hyoscyamus niger (Parker et al., 1950), and of tuberization in a few tuberous plants, Solanum tuberosum (Machackova et al., 1998) and Begonia evansiana (Esashi and Nagao, 1958; Esashi, 1966).

It was reported that photoperiodism involves a rhythmic change of the response of flowering and tuberization to light. Circadian rhythms in the response to a light-break in flowering have been well demonstrated in some other plants including SDPs as Perilla (Carr, 1952), Chenopodium rubrum (Cumming et al., 1965), Xanthium (Moore et al., 1967) and Pharbitis (Takimoto and Hamner, 1964) and LDPs as Hyoscyamus niger (Hsu and Hamner, 1967) and Lolium temulentum (Perilleux et al., 1994). Esashi (1963) reported that circadian rhythms of light-break in the formation of aerial tubers, which were induced by short daylength, in Begonia evansiana were also observed.

We report here the circadian rhythms to light-break under short daylength of rhizome enlargement in lotus.

\section{MATERIALS AND METHODS}

\section{Plant Materials}

Open pollinated seeds of $N$. nucifera 'Chugoku' were used in all experiments. The seeds were prepared for germination by soaking in conc. $\mathrm{H}_{2} \mathrm{SO}_{4}$ for $3 \mathrm{hrs}$ and rinsed with distilled water. They were then soaked in distilled water for one day at $25^{\circ} \mathrm{C}$. After removing softened seed coats, the seeds were incubated in distilled water at $25^{\circ} \mathrm{C}$ under continuous fluorescent light (approximately $40 \mu \mathrm{mol} \mathrm{m} \mathrm{m}^{-2} \mathrm{~s}^{-1}$ ) until germination (nine 
days). Five seedlings for one treatment were transplanted into sandy soil containing 48g slow-release fertilizer $(\mathrm{N}: \mathrm{P}: \mathrm{K}=10: 10: 10 \%)$ per plastic container $(45 \times 32 \times 23.5 \mathrm{~cm})$. The containers were filled with water, and the water was replaced weekly.

Rhizome enlargement index ( = maximum internode diameter/internode length) was calculated as a parameter of rhizome growth in each internode after cultivation. The maximum rhizome enlargement index among all the internodes observed in each plant was used for calculating the average values. Starch grains accumulation in the cells of the youngest rhizomes was observed under a light microscope.

\section{Light-break treatments}

Nine-days old seedlings were transplanted and grown for 2 weeks under $14 \mathrm{hr}$ daylength with $8 \mathrm{hr}$ natural light (8:00-16:00) and $6 \mathrm{hr}$ supplemental white light at $30^{\circ} \mathrm{C}$ in a phytotron glass room of the Biotron Institute, Kyushu University. They were subsequently cultivated for 2 weeks under 10 ( $8 \mathrm{hr}$ natural light (8:00-16:00) and $2 \mathrm{hr}$ supplemental white light), 8 ( $8 \mathrm{hr}$ natural light (8:00-16:00)) or $4 \mathrm{hr}$ ( $4 \mathrm{hr}$ natural light (10:00-14:00)) daylength. A single light-break for 5 minutes by red light was given after $2,4,6,8,10,12,14$, 16 or $18 \mathrm{hrs}$ from the beginning of the dark period. A white fluorescent tube (Mitsubishi FL20SSW/18) was used for white light. The red light was given from a red fluorescent tube (National FL20SR) filtered through a 3-mm thick red acrylic plate (Acrylite \#102; Mitsubishi Rayon Co Ltd., Tokyo).

\section{RESULTS}

Three types of rhizome growth were obtained; low values $(<0.2)$ of maximum rhizome enlargement index with or without accumulation of starch grains and the high values $(>0.2)$ with starch grains accumulation in the cells of the youngest rhizome (Fig. 1). Maximum responsiveness to red light-break was, therefore, determined by the index and percentage of the plants with starch grains accumulation.

The plants grown under $10 \mathrm{hr}$ daylength with $5 \mathrm{~min}$ red light-break after 2 hrs of the beginning of darkness showed high value of 0.66 in maximum rhizome enlargement index and starch grains accumulation was observed in all the plants (100\%) similarly to those without light break (Fig. 2A). The later the light-break treatment from the beginning of the dark period was given, the lower the maximum rhizome enlargement index values were until the treatments after $10 \mathrm{hrs}$ of darkness. More than a half of the plants accumulated starch grains in their rhizome cells whenever the light-break treatment was given except for that given at 10 hrs after the beginning of the dark period. The lowest value (0.18) of the index was observed with light-break given after $10 \mathrm{hrs}$ of darkness, and the cells of the youngest rhizomes contained no starch grains in all the plants $(0 \%)$.

Neither rhizome enlargement nor starch grains
A
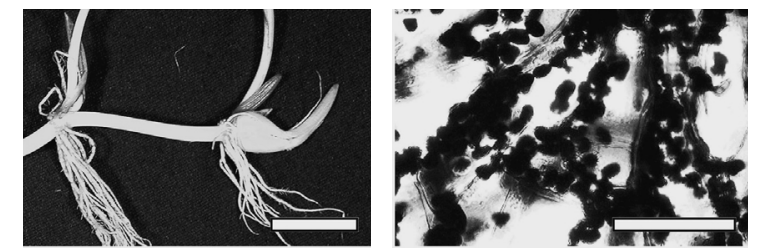

$\mathrm{B}$
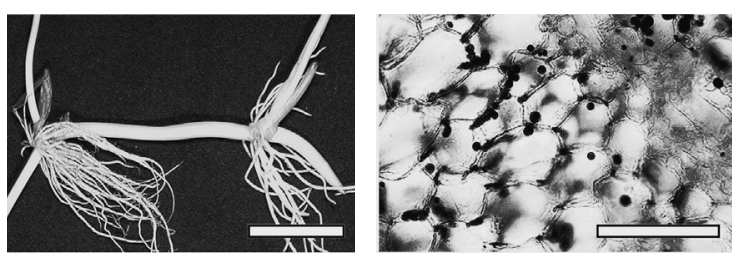

C
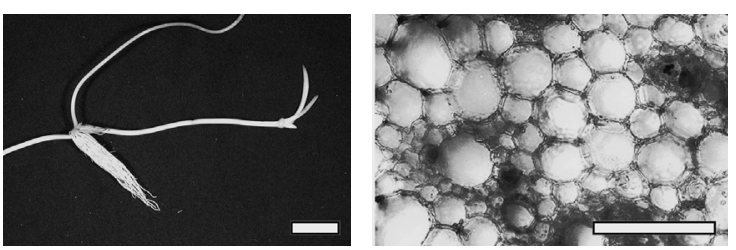

Fig. 1. Three types of rhizomes observed in maximum rhizome enlargement index and starch grains accumulation in the cells of the youngest rhizome. A; maximum rhizome enlargement index $>0.2$ with starch grains accumulation, $\mathrm{B}$; maximum rhizome enlargement index $<0.2$ with starch grains accumulation and C; maximum rhizome enlargement index $<0.2$ with no starch grains accumulation. Bars indicate $2.5 \mathrm{~cm}$ for left row and $100 \mu \mathrm{m}$ for right row.

A

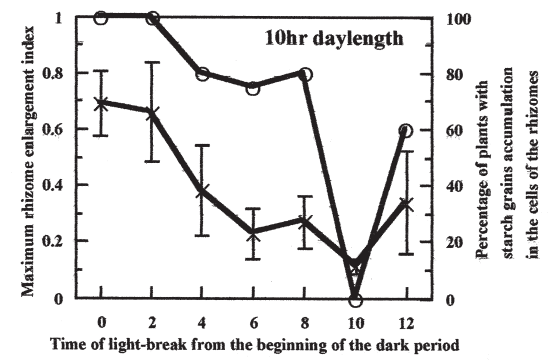

B
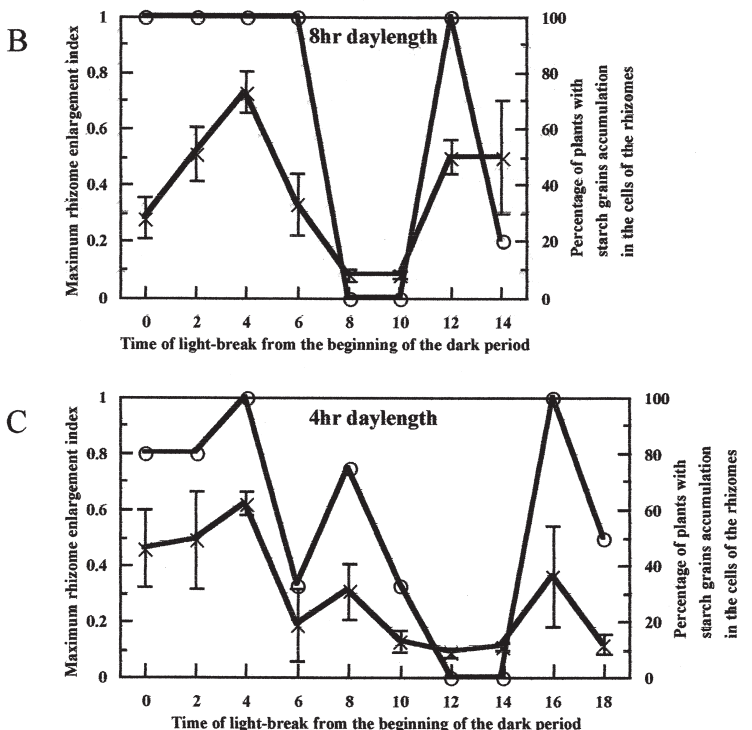

Fig. 2. Effect of time of light-break under different daylengths on maximum rhizome enlargement index of main rhizomes and percentage of the plants with starch grains accumulation in the cells of the youngest rhizome grown under 10 (A), 8 (B) and $4 \mathrm{hr}(\mathrm{C})$ daylengths. $\times$; average of maximum rhizome enlargement index, $\bigcirc$; percentage of the plants with starch grains accumulation. Vertical bars represent \pm s.e. 
accumulation was observed in the plants when the light-break treatment was given 8 and 10 hrs after the beginning of the dark period under 8hr daylength (Fig. 2B). The light-break treatments given at other times brought rhizome enlargement $(>0.2)$ and/or starch grains accumulation.

No starch grains accumulation with maximum rhizome enlargement index of less than 0.2 was found only in the plants with the light-break treatments given 12 and $14 \mathrm{hrs}$ after the beginning of the dark period (Fig. 2C). Although maximum rhizome enlargement indices of less than 0.2 were also found in the plants with the light-break treatments after 6,10 and 18 hrs of darkness, more than $30 \%$ of the plants accumulated starch grains in their cells of the rhizomes.

\section{DISCUSSION}

It was found in the present study that the most effective times of light-break varied with daylength in lotus. A red light of one minute as a light-break was, however, most inhibitory at approximately the 8th hr of the dark periods irrespective of daylength (12, 8 and $4 \mathrm{hr}$ daylength) in aerial tuber formation of Begonia evansiana (Esashi, 1963). Lumsden et al. (1982) found that in dark-grown seedlings of Pharbitis nil exposed to a single photoperiod of less than about 6 hrs the first maximum inhibitory response of flowering to a light-break always occurred at approximately 15 hrs from the beginning of the light period. When the dark-grown seedlings were exposed to a single photoperiod longer than $6 \mathrm{hrs}$, it was always at $9 \mathrm{hrs}$ after the end of the light period. It has been interpreted that the dark-grown seedlings initiate circadian rhythm in which the most effective times of light-break is at about $15 \mathrm{hrs}$ from light period by light-on signal. The rhythm to light-break is, however, suspended and maintained when the dark-grown seedlings were exposed to a single light longer than $6 \mathrm{hrs}$, and the suspension is released by the transition from the light to dark. The released rhythm reaches its maximum responsiveness about 9 hrs after the beginning of light. This interpretation from the results of Pharbitis nil is quite similar to those of Xanthium strumarium (Papenfuss and Salisbury, 1967). Maximum responsiveness of inhibition of rhizome enlargement in lotus to light-break under 10 and $8 \mathrm{hr}$ daylengths occurred 10 and $8-10$ hrs after the beginning of the dark period, respectively, whereas that under $4 \mathrm{hr}$ daylength occurred 16-18 hrs after the beginning of the light period. The interpretation for Pharbitis nil and Xanthium strumarium seems to be applied to present results in lotus.

The plant must perceive light to act such a rhythmic response to light-break and it has been well recognized that phytochrome is involved in light perception. It was recently reported that phytochrome B mediated the light break-delayed flowering in Oryza sativa (Ishikawa et al., 2005). Light exposure for $10 \mathrm{~min}$ in the middle of a $14 \mathrm{hr}$ night (10 hr daylength) strongly suppressed the mRNA expression of $H d 3 a$, a positive regulator of the flowering, in the wild type, but the phyB mutation abolished the light break effect. The phyA and phyC mutation, however, had no effect on the expression of Hd3a mRNA. Phytochrome B may play an important role in the perception of the light break, and it may be also involved in the rhythmic response to light-break in lotus.

It is concluded that rhythmic response is involved in the responsiveness to light-break in rhizome enlargement of lotus.

\section{ACKNOWLEDGEMENTS}

We acknowledge the financial supports by Matsushima Horticultural Development Foundation, Japan, and Grant-in-Aid from the Ministry of Education, Science, Sports and Culture of Japan. We gratefully thank Mr. M. Hamakoga for his technical assistance in light break experiments by supplying the experimental device.

\section{REFERENCES}

Borthwick H. A., S. B. Hendricks and M. W. Parker 1948 Action spectrum for photoperiodic control of floral initiation of a long-day plant, wintex barley (Hordeum vulgare). Bot. Gaz., 110: 103-118

Carr, D. J. 1952 The photoperiodic behaviour of short-day plants. Physiol. Plant., 5: 70-84

Cumming, B. G., S. B. Hendricks and H. A. Borthwick 1965 Rhythmic flowering responses and phytochrome changes in a selection of Chenopodium rubrum. Can. J. Bot., 43 : 825-853

Esashi, Y. 1963 Studies on the formation and sprouting of aerial tubers in Begonia evansiana Andr. VIII. Dual effect on tuberization of near infrared light given in dark periods. Plant Cell Physiol., 4: 135-143

Esashi, Y. 1966 The relation between red and blue or far-red lights in the night-interruption of the photoperiodic tuberization in Begonia evansiana. Plant Cell Physiol., 7: 405-414

Esashi, Y. and M. Nagao 1958 Studies on the formation and sprouing of aerial tubers in Begonia evansiana Andr. I. Photoperiodic conditions for tuberization. Sci. Rep. Tohoku Univ. 4th Ser (Biol)., 24: 81-88

Ewing, E. E. and P. C. Struik 1992 Tuber formation in potato: Induction, initiation and growth. Hort. Rev., 14: 89-198

Hamner, K. C. and E. M. Long 1939 Localization of photoperiodic perception in Helianthus tuberosus. Bot. Gaz., 101: 81-90

Hsu, J. C. S. and K. C. Hamner 1967 Studies on the involvement of an endogenous rhythm in the photoperiodic response of Hyoscyamus niger. Plant Physiol., 42: 725-730

Ishikawa, R., S. Tamaki, S. Yokoi, N. Inagaki, T. Shinomura, M. Takano and K. Shimamoto 2005 Suppression of the floral activator $\mathrm{Hd} 3 \mathrm{a}$ is the principal cause of the night break effect in rice. Plant Cell., 17: 3326-3336

Lumsden, P. J., B. Thomas and D. Vince-Prue 1982 Photoperiodic control of flowering in dark-grown seedlings of Pharbitis nil Choisy. The effect of skeleton and continuous light photoperiods. Plant Physiol., 70: 277-282

Machackova, I., T. N. Konstantinova, L. I. Sergeeva and V. N. Lozhnikova 1998 Photoperiodic control of growth, development and phytohormone balance in Solanum tuberosum. Physiol. Plant., 102: 272-278

Masuda, J., T. Urakawa, Y. Ozaki and H. Okubo 2006 Short photoperiod induces dormancy in lotus (Nelumbo nucifera). Ann. Bot., 97: 39-45

Moore, P. H., H. B. Reid and K. C. Hamner 1967 Flowering 
responses of Xanthium persylvanicum to long dark periods. Plant Physiol., 42: 503-509

Papenfuss, H. D. and F. B. Salisbury 1967 Aspects of clock restting in flowering of Xanthium. Plant Physiol., 42: 1562-1568

Parker M. W., S. B. Hendricks, H. A. Borthwick and N. J. Scully 1946 Action spectrum for the photoperiodic control of floral initiation of short-day plants. Bot. Gaz., 108: 1-26

Parker, M. W., S. B. Hendricks and H. A. Borthwick 1950 Action spectrum for the photoperiodic control of floral initiation of the long-day plant Hyoscyamus niger. Bot. Gaz., 111:

\section{$242-252$}

Perilleux, G., G. Bernier and J.-M. Kinet 1994 Circadian rhythms and the induction of flowering in the long-day grass Lolium temulentum L. Plant Cell Environ., 17: 755-761

Snyder, R. G. and E. E. Ewing 1989 Interactive effect of temperature, photoperiod, and cultivar on tuberization of potato cuttings. HortScience, 24: 336-338

Takimoto, A. and K. C. Hamner 1964 Effect of temperature and pre-conditioning on photoperiodic response of Pharbitis nil. Plant Physiol., 39: 1024-1030 